Viral Etiology of Acute Lower Respiratory Tract Infections in Hospitalized Children in Nagasaki, a Regional City of Japan in 2013 to 2015

Tomoyuki Hasuwa, MD, ${ }^{1}$ Fumiko Kinoshita, MD, ${ }^{2}$ Sadatomo Harada, MD, ${ }^{2}$ Kazuhisa Nakashima, MD, PhD, ${ }^{2}$ Keisuke Yoshihara, $\mathrm{PhD},{ }^{3}$ Yuichirou Toku, $\mathrm{MD},{ }^{2}$ Hiroyuki Moriuchi MD, $\mathrm{PhD}^{1}$ and Lay Myint Yoshida, MB BS, $\mathrm{PhD}^{3}$

1. Department of Pediatrics, Graduate School of Biomedical Sciences, Nagasaki, Nagasaki University Japan

2. Department of Pediatrics, Nagasaki Harbor Medical Center, Nagasaki, Japan

3. Department of Pediatric Infectious Diseases, Institute of Tropical Medicine, Nagasaki University, Nagasaki, Japan

Correspondence to H. Moriuchi, Department of Pediatrics, Graduate School of Biomedical Sciences, Nagasaki University, 1-7-1 Sakamoto, Nagasaki 852-8501, Japan.

Tel: +81-95-829-7297 Fax: +81-95-819-7301

E-mail: hiromori@nagasaki-u.ac.jp

Keywords: acute lower respiratory tract infections, respiratory pathogen, epidemiology, multiplex PCR, enterovirus D68

Abbreviated title: Acute Lower Respiratory Tract Infections in Japan Running title: Acute Lower Respiratory Tract Infections 


\section{Viral Etiology of Acute Lower Respiratory Tract Infections in Hospitalized Children in Nagasaki, a Regional City of Japan in 2013 to 2015}

Background: Acute lower respiratory tract infections (ALRIs) are the most common disease for hospitalized children in Japan. The aim of this study was to identify etiological viruses in children hospitalized for ALRIs and to demonstrate epidemiologic and clinical characteristics in Japan.

Methods: During a 2-year period from February 2013 to January 2015, we collected nasopharyngeal swab specimens from almost all hospitalized children with ALRIs in Nagasaki, a regional city of Japan, and its environs. Viruses were detected by multiplex polymerase chain reaction from these samples.

Results: We detected one or more viruses from 259 (69\%) of 374 patients, 227 (60.9\%) of whom were infected with a single virus, 30 (8.0\%) with 2 , and 2 $(0.5 \%)$ with 3 viruses. Detected viruses in this study were rhinovirus (46.4\%), respiratory syncytial virus (RSV) (29.7\%), human metapneumovirus (6.8\%), parainfluenza virus (5.5\%), enterovirus D68 (3.4\%), influenza virus (2.7\%), adenovirus (2.4\%), bocavirus (2.0\%), and Coxsackie virus (1.0\%). We detected a seasonal shift in RSV outbreaks from the 2013-2014 to the 2014-2015 seasons. There was no significant difference in clinical course and severity among those viruses. Patients with a history of asthma or underlying diseases were older and more frequently required oxygen therapy than previously healthy patients.

Conclusions: Viral etiology in hospitalized children with ALRIs in Nagasaki, Japan was similar to that in many other countries. Enterovirus D68, which was recently recognized as a causative agent of severe ALRIs, was also identified in this study area. Severity of ALRIs may depend on underlying disease rather than type of etiological virus. 


\section{Viral al Etiology of Acute Lower Respiratory Tract Infections in Hospitalized Children in a Regional City of Japan, Nagasaki 2013-2015}

\section{INTRODUCTION}

Acute lower respiratory tract infections (ALRIs) are the most important cause of deaths for children in developing countries and are the most common cause of hospitalization in developed countries..$^{1,2}$

A broad range of respiratory viruses is responsible to the mortality and morbidity. Human rhinovirus (HRV) and respiratory syncytial virus (RSV) have been widely recognized as common pathogens for ALRIs. ${ }^{3,}, 4$ Human metapneumovirus (hMPV) that was discovered in the Netherland in 2001 and enterovirus (EV)-D68 that prevailed across the USA in 2014 have been recently recognized as important respiratory pathogens.5, 6 These respiratory viruses have been shown to cause severe respiratory illnesses for patients with viral co-infections, congenital heart disease, prematurity, or a history of wheezing/asthma. ${ }^{7-9}$ During the outbreak in Japan in 2015, EV-D68 was reported to cause severe respiratory illness for patients with asthma exacerbation and associated with acute flaccid paralysis (AFP).9, 10, 11

Technologies used to detect those agents may also influence study results. Multiplex PCR has been reportedly useful to detect a wide range of viruses and has been used in many studies, ${ }^{12-16}$ However, their epidemiological features and clinical impacts may be different among study areas. ${ }^{12-14}$ While viral etiology and clinical-epidemiological features have been repeatedly reported from tropical or subtropical regions in Asia, ${ }^{15}, 16$ there have been fewer studies from temperate regions in Asia. Furthermore, most of them were performed in a single core hospital or a research center to which samples are collected from some affiliated hospitals. Therefore, results obtained from those studies might not always reflect an actual regional overview of viral etiology in children hospitalized for ALRIs.

The aim of this study was to identify etiological viruses and to demonstrate epidemiologic and clinical characteristics of children hospitalized for ALRIs in two main hospitals that admit almost all pediatric patients who live in Nagasaki city and its environs, the westernmost part of 
Japan. In addition to several sets of multiplex PCR assays, we performed a supplementary PCR assay for detection of EVs, including EV-D68. Thus, the results of this study will represent a regional overview of viral etiology as well as epidemiologic and clinical characteristics of ALRIs in hospitalized children in Japan.

\section{MATERIALS AND METHODS}

Nagasaki City with a population of approximately 430,000, including 15,500 (3.6\%) children less than 5 years of age in 2015 , is located in the westernmost part of Japan and has a temperate climate. This prospective study was performed in the two main hospitals in Nagasaki. One is a secondary hospital (Nagasaki Harbor Medical Center) that mainly admits pediatric patients with no underlying disease. The other is a university hospital (Nagasaki University Hospital) that is responsible for hospital care of those with some underlying disease. If children who live in Nagasaki city and its environs need hospital care, almost all of them are admitted in either of the two hospitals.

Patients with ALRIs who were admitted to the pediatric department at either of the two hospitals during a 2-year period from February 2013 to January 2015 were eligible for this study. Those who stayed in neonatal intensive care unit (NICU) or whose guardians did not give informed consent were excluded from this study.

ALRI was defined as acute onset of wet cough, wheeze, or respiratory distress symptoms, with or without fever at the time of admission. Chest radiography was performed in all hospitalized patients with ALRIs at admission. Pneumonia was defined as the presence of alveolar consolidation on the chest radiographs (CXR), which were read by pediatricians in the hospitals.

Nasopharyngeal swabs (NPSs) were collected from enrolled patients within 24 hours of hospital admission, placed in viral transport media, and stored at $-80^{\circ} \mathrm{C}$ in the laboratory at Nagasaki University Hospital. We extracted viral nucleic acids using a QIAamp viral RNA Mini Kit (QIAGEN Inc., Valencia, CA). 
The following 4 sets of multiplex PCR assays were performed for each sample to detect the following 13 respiratory viruses: (Set-1) RSV, influenza A/B virus (FluAV/FluBV), and hMPV; (Set-2) parainfluenza virus (PIV) types 1-4; (Set-3) HRV and human coronavirus OC43/229E (HCoV); and (Set-4) adenovirus (AdV) and human bocavirus (HBoV). The details of the multiplex PCR assays were published elsewhere. ${ }^{17,} 18$

Samples negative for the above 4 sets of multiplex PCR assays were screened for genus EV by using another set of RT-PCR that targets the 5 '-noncoding region (5'-NCR). The specific primer pair, DK001 (forward 5' CAAGCACTTCTGTTTCCC) and DK004 (reverse 5' CACGGACACCCAAAGTAGT), was utilized as previously described.19, 20 Amplicons of the PCR products were run on $2 \%$ agarose gel for confirmation. EV 5'-NCR PCR-positive samples were purified with Exo-SAP-IT (Thermo Fisher Scientific, Waltham, MA, USA), and subjected to sequencing reactions by using BigDye terminator ver.1.1 (Applied Biosystem, Foster City, CA, USA). Nucleotide sequence analysis was performed with 3730 DNA Analyzer (Applied Biosystem, Foster City, CA, USA). Nucleotide sequences of EV 5'-NCR were aligned and edited using ClustalW algorism implemented within MEGA ver 6.0.21 The nucleotide sequences of 5'-NCR positive cases were determined as EV-D68, HRV, and ge (CV) for the closest EV species-match through BLAST search (https://blast.ncbi.nlm.nih.gov/Blast.cgi).

Patient information and clinical data were extracted from medical chart. We statistically compared clinical features and severity between patients with no detectable virus and those infected with one of the top five viruses. Based on the past medical history, patients with any detectable virus were classified into the following three groups: previously healthy patients, those with a history of asthma, and those with underlying diseases other than asthma. Underlying diseases included genetic syndrome, congenital heart disease, gastroesophageal reflex disease, congenital tracheal stenosis, immunodeficiency, premature birth, and severe mental and physical disabilities. We compared disease severity among those patient groups. 
Statistical analyses were computed using JMP Pro 12 (SAS Institute Inc., Cary, NC). Clinical feature and severity of patients according to viral etiology were compared using the logistic regression analysis. Clinical features and severity of patients according to the past medical conditions were compared using the chi-square test for categorical variables and using the student's t-test for continuous variables. Statistical significance was defined as $P$ value $<0.05$.

Guardians of all study subjects gave written informed consent for enrollment of this study. This study was approved by the institutional review boards of Nagasaki Harbor Medical Center and Nagasaki University Hospital, Nagasaki, Japan.

\section{RESULTS}

During the study period, 601 and 366 patients were hospitalized in Nagasaki Harbor Medical Center and Nagasaki University Hospital, respectively. A total of 373 patients (259 in Nagasaki Harbor Medical Center and 114 in Nagasaki University Hospital) were enrolled in the study. Their median age was 15 months (interquartile range 6-34), and 193 (52\%) were male. Among them, $230(61.7 \%)$ patients were positive in the first multiplex PCR. Out of 142 patients who were negative in the first PCR, 36 patients were positive in the second EV 5'-NCR PCR. However, virus species was not identified in 7 of them by sequencing; therefore, they were regarded as patients with no detectable virus (Figure 1). Eventually, 259 (69.4\%) of 373 patients had one or more viruses: $227(60.9 \%)$ of whom were infected with a single virus, 30 $(8.0 \%)$ had two, and $2(0.5 \%)$ had three viruses.

The most frequently detected virus was HRV $(n=136)$, followed by

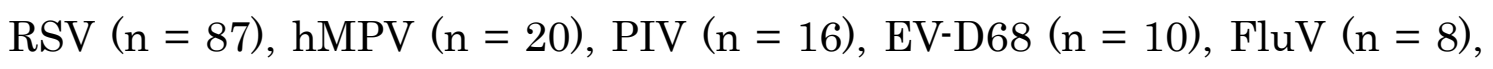
$\mathrm{AdV}(\mathrm{n}=7), \mathrm{BoV}(\mathrm{n}=6)$, and $\mathrm{CV}(\mathrm{n}=3)$. $\mathrm{HCoV}$ was not detected in this study. The breakdown of 16 PIVs was as follows: genus respirovirus (PIV1, $\mathrm{n}=4$; PIV3, $\mathrm{n}=7$ ) and genus rubulavirus (PIV2, $\mathrm{n}=1$; PIV4, $\mathrm{n}=3$ ).

Figure 2 shows the seasonal distribution of the top five viruses (HRV, RSV, hMPV, respirovirus [PIV1, PIV3] and EV-D68) detected in this study. HRV was detected throughout the year except for the midwinter around 
February. RSV was epidemic in the winter of 2013 and in the summer to fall of 2014. hMPV was detected in a cluster around the spring of 2013, but otherwise irregularly. Respirovirus (PIV1, PIV3) was detected mainly during the spring to fall of 2014. EV-D68 was detected in the spring and early fall of 2013 and in October 2014.

Clinical features and severity were compared between patients with no detectable virus and those with any detectable virus or those with either of the above top five viruses (Table 1). Patients with any detectable virus more frequently had a history of asthma (18.8 vs $6.9 \%, \mathrm{p}<0.001)$, required oxygen supplement (52.8 vs $40.9 \%, \mathrm{p}=0.025)$ and less frequently developed pneumonia ( 44.0 vs $61.7 \%, \mathrm{p}=0.001$ ) than those with no detectable virus. There was no significant difference in age, the presence of underlying diseases and the length of hospital stay regardless of whether virus was detected or not. Three patients with no detectable virus, but no patient with any detectable virus, needed management in ICU. Two of them had severe mental and physical disabilities with tracheostomy, and the other was a five-month-old infant born with extremely low birth weight.

RSV-positive patients were younger (median age: $8.5 \mathrm{mth}$ vs $15.5 \mathrm{mth}, \mathrm{P}<0.001)$ and less frequently had underlying diseases (13.5 vs $25.4 \%, \mathrm{P}<0.001)$ than those with no detectable virus. HRV or EV-D68 infected patients had a history of asthma more frequently than those infected with other viruses. A significantly lower proportion of RSV-infected patients were diagnosed with pneumonia, and higher proportion required oxygen supplement. There were some differences in the previous history of asthma, the presence of underlying diseases, diagnosis of pneumonia and requirement of oxygen supplement but there were no differences in the length of hospital stay and PICU stay between patients with no detectable virus and those with the respective viruses. There was no fatal case during the study period.

We compared disease severity among three patient groups: previously healthy patients, those with a history of asthma, and those with underlying diseases other than asthma. (Table 2). Patients with a history of asthma or underlying diseases were older and more frequently required 
oxygen therapy than those previous healthy. The length of hospital stay was significantly longer in patients with underlying diseases than in other patient groups (median 7 days vs 5 days $\mathrm{P}<0.001$ ).

\section{DISCUSSION}

In this study, we detected one or more viruses from approximately $70 \%$ of patients, similarly to previous studies from Europe, East Asia, and Southeast Asia. ${ }^{12,15,16,22,23}$ We observed an unexpected shift of RSV outbreak and detected EV-D68 in the study period before EV-D68-associated AFP attracted attention of pediatricians in Japan.

HRV was the most frequently detected virus from children hospitalized for ALRIs in our study as well as previous studies. 15, 16, 23, 24 In the temperate climate zones, such as this study site, HRV is detected throughout the year, especially in spring and fall. ${ }^{25}$ We also detected HRV in all seasons, but less frequently in midwinter. Many studies reported association of HRV with wheeze or asthma in children.26, 27 Similarly, we observed that patients infected with HRV more frequently had a history of asthma than patients with no detectable virus, although this study did not specifically investigate the association of respiratory viruses with asthma exacerbation.

RSV was the second most common virus detected in this study. RSV frequently causes severe ALRI that requires hospitalization in young children. ${ }^{28,}{ }^{29}$ In this study, patients infected with RSV were significantly younger, and less frequently diagnosed with pneumonia. RSV disease typically prevails between fall and winter in the temperate climate regions, 4 , 29 as we observed in the 2013-2014 season. Interestingly, however, an RSV outbreak peaked in August and September in the 2014-2015 season. The outbreak is demonstrated by 5 identified cases (Figure 2). A similar shift in RSV outbreak has been observed among many regions in Japan, except for Hokkaido and Okinawa, thereafter. ${ }^{30}$ In Hokkaido, the northernmost part of Japan located at the boundary of a cool-temperate zone to subarctic zone, there is no apparent seasonal pattern and RSV is detected slightly but 
continuously all year round. In Okinawa, the southernmost part of Japan located at a subtropical zone, RSV outbreak is observed in summer similarly to other subtropical or tropical countries. ${ }^{31,}{ }^{32}$ Although it is not clear why epidemiology of RSV infection in Japan has changed like that, our 2-year study precisely detected such a trend.

FluV, an important respiratory pathogen, has been frequently detected in hospitalized children in Asia 16, 22, 23; however, it was detected in only 8 patients (five for FluA and three for FluB) in this study, while FluVs circulated in Nagasaki as usual. In Japan, most children with influenza receive precise diagnosis by rapid detection of FluV antigen and start neuraminidase inhibitor treatment within $24 \mathrm{~h}$ after the onset of illness. It was reported that early treatment with neuraminidase inhibitors widely implemented in Japan had probably reduced the number of severe and fatal cases of H1N1/09-associated disease. ${ }^{33}$ That may also contributed to much fewer hospitalized cases in this study than in other studies in Asia.

hMPV was the third common virus detected in this study. Previous studies have reported that hMPV was prevalent during late winter and spring in temperate climates. ${ }^{34,} 35$ In this study, however, we detected hMPV between May and August in 2014; therefore, the outbreak pattern may vary from year to year.

PIVs are also important respiratory viruses, ${ }^{36,37}$ and each type of PIVs has different clinical and epidemiological features. PIV-3 is usually the most common in hospitalized children with ALRIs, ${ }^{37}$ as in our study.

$\mathrm{HCoV}$ was not detected in this study. It might be partly because our PCR sets only targeted HCoV-OC43 and HCoV-229E, but not HCoV-NL63 and $\mathrm{HCoV}-\mathrm{HKU} 1$. Since there is annual variation in the circulation of the respective $\mathrm{HCoV}$ strains, ${ }^{38}$ it is possible that $\mathrm{HCoV}-\mathrm{NL} 63$ or $\mathrm{HCoV}-\mathrm{HKU} 1$ prevailed in this study period.

EV-D68, once recognized as only a rare respiratory virus, ${ }^{39}$ has been increasingly reported to cause severe respiratory illness worldwide since around 2010.40 Moreover, it has been associated with AFC since 2014. ${ }^{41,}{ }^{42}$ Kaida et al. firstly reported EV-D68 upsurge in 2010 and re-emergence in 2013 and 2015 in Osaka City, Japan. ${ }^{43}$ Nationwide EV-D68 outbreak 
occurred in the fall of 2015 when the number of hospitalized children for asthma exacerbation and treated with mechanical ventilation in ICU were increased.10 However, epidemiological features and clinical impacts of EV-D68 in Japan before 2015 remain largely unknown. Therefore, we tried to detect EV-D68 among the first PCR-negative samples. EV-D68 was detected in 10 patients (nine positive for EV-D68 only and one positive for EV-D68 and HRV), mainly in the early fall of 2013. There was no case of AFP reported in the study sites during this study period, although three patients were diagnosed with AFP in our hospital in the fall of 2015.44 EV-D68-positive patients had a history of asthma frequently in this study but none of them needed ICU management, as previously reported during the outbreak in the fall of $2015.9,10$

In this study, severity of ALRIs, such as the diagnosis of pneumonia, the median length of hospital stay, requirement of oxygen supplement, and ICU management, were influenced by medical background, but not virus detection results, as previously reported. ${ }^{45,46}$

This study has some limitations. First, this study did not considered that effect of bacterial infections. The multiplex PCRs used did not target bacterial pathogens that can cause severe ALRIs by themselves or in conjunction with viral pathogens. ${ }^{18,} 28$ We collected few blood cultures in this study, since blood cultures in patients with ALRI were rarely positive. Thus, it was unclear to what extent bacterial pathogens contributed to clinical course in this study. Second, PCR can detect both etiological and non-etiological viruses. 47,48 Since we used nasopharyngeal sample for the testing, we were not able to confirm whether or not the detected viruses were the etiological agents. Third, patients with no detectable virus necessarily had no virus, even several sets of multiplex PCRs are unable to comprehensively detect all respiratory viruses. Fourth, the second PCR to detect EV was tested only for the first multiplex PCR-negative patients. It is likely that some patients who were positive in the first multiplex PCR also got infected with EV. Lastly, we were unable to analyze the significance of interstitial pneumonia that most likely caused by viruses, since it was difficult to standardize interpretation of radiographic findings, such as 
ground-glass opacity and reticular shadow characteristic of interstitial pneumonia in this study. 49

In conclusion, this two-year surveillance showed an overview of viral etiology, epidemiologic and clinical characteristics in children hospitalized for ALRIs in a regional city in Japan. HRV was most frequently detected virus among patients. An unexpected shift of RSV outbreak was observed in this study period. EV-D68 was detected in this study period before EV-D68-associated AFP attracted attention to pediatricians. Severity of ALRIs seemed to depend on the presence of underlying disease rather than type of respiratory virus detected.

\section{ACKNOWLEDGEMENTS}

We thank Ms. Rina Shiramizu from Institute of Tropical Medicine for her excellent technical assistance and all pediatricians from the study hospitals for patients' recruitment and sample collection.

\section{FIGURE LEGENDS}

Fig. 1 Flow chart of the study for the detection of viral pathogens $1^{\text {st }}$ PCR indicates 4 sets of multiplex RT-PCR or PCR for the detection of HRV, RSV, hMPV, PIV1-4, FluA/BV, AdV, BoV, and HCoV (OC43/229E).

$2^{\text {nd }}$ PCR indicates EV 5'-NCR PCR for the detection of genus enterovirus.

Sequencing of $2^{\text {nd }}$ PCR amplicons revealed EV-D68, CV or HRV in 29 cases, but failed to identify species in 7 cases. 
Fig. 2 Monthly distribution of the 5 major viruses in Japan between February 2013 and January 2015 in hospitalized children with ALRT disease.

Case numbers in each month are shown for HRV, RSV, hMPV, respirovirus (PIV1, PIV3) and EV-D68. 
1. Liu L, Oza S, Hogan D, et al. Global regional, and national causes of under-5 mortality in 2000-15: an updated systematic analysis with implications for the Sustainable Development Goals. Lancet. 2016; 388: 3027-3035.

2. Nair H, Nokes DJ, Gessner BD, et al. Global and regional burden of hospital admissions for severe acute lower respiratory infections in young children in 2010: a systematic analysis. Lancet. 2013; 381: 1380-1390

3. Hayden FG. Rhinovirus and the lower respiratory tract. Rev Med Virol. 2004; 14: 17-31.

4. Stensballe LG, Devasundaram JK, Simoes EAF, et al. Respiratory syncytial virus epidemics: the ups and downs of a seasonal virus. Pediatr Infect Dis J. 2003; 22: S21-S32

5. Bernadette G, van den Hoogen, Jan C, et al. A newly discovered human pneumovirus isolated from young children with respiratory tract disease. Nat. Med. 2001; 7: 719-724.

6. Midgley CM, Watson JT, Nix WA, et al. Severe respiratory illness associated with a nationwide outbreak of enterovirus D68 in the USA (2014): a descriptive epidemiological investigation. Lancet Respir Med. 2015; 11: 879-887.

7. Rodriguez DA, Rodrigues-Martines CE, Cardenas AC, et al. Predictors of severity and mortality in children hospitalized with respiratory syncytial virus infection in a tropical region. Pediatr Pulmonol. 2014; 49: 269-276

8. Harada Y, Kinoshita F, Yoshida LM, et al. Does respiratory virus coinfection increases the clinical severity of acute respiratory syncytial virus? Pediatr Infect Dis J. 2013; 32: 441-445.

9. Schuster JE, Miller JO, Selvarangan R, et al. Severe enterovirus 68 respiratory illness in children requiring intensive care management. $J$ Clin Virol. 2015; 70: 77-82.

10. Korematsu S, Nagashima K, Sato Y, et al. "Spike" in acute asthma exacerbateions during enterovirus D68 epidemic in Japan: A nation-wide survey. Allergol Inter. 2018; 67: 55-60.

11. Chong PF, Kira R, Mori H, et al. Clinical features of acute flaccid myelitis temporally associated with an enterovirus D68 outbreak: results of a 
nationwide survey of acute flaccid paralysis in Japan, August-December 2015. Clin Infect J. 2018; 66: 653-664.

12.Legg JP, Warner JA, Johnston SL, et al. Frequency of detection of picornaviruses and seven other respiratory pathogens in infants. Pediatr Infect Dis J. 2005; 24: 611-616.

13. Litwin CM, Bosley JG. Seasonality and prevalence of respiratory pathogens detected by multiplex PCR at a tertiary care medical center. Arch Virol. 2014; 159: 65-72.

14. Marcone DN, Ellis A, Videla C, et al. Viral etiology of acute respiratory infections in hospitalized and outpatient children in Buenos Aires, Argentina. Pediatr Infect Dis J. 2013; 32: e105-e110.

15. Gilles G, Goyet S, Chheng ET, et al. Acute viral lower respiratory tract infections in Cambodian children: clinical and epidemiologic characteristics. Pediatr Infect Dis J. 2013; 32: e8-e13

16. Tran DN, Trinh QD, PHAM NTK, et al. Clinical and epidemiological characteristics of acute respiratory virus infections in Vietnamese children. Epidemiol Infect. 2016; 144: 527-536.

17. Yoshida LM, Suzuki M, Yamamoto T, et al. Viral pathogen associated with acute respiratory infection in central Vietnamese children. Pediatr Infect Dis J. 2010; 29: 75-77.

18. Vu HT, Yoshida LM, Suzuki M, et al. Association between nasopharyngeal load of Streptococcus pneumoniae, in viral coinfection, and radiologically conformed pneumonia in Vietnamese children. Pediatr Infect Dis J. 2011; 30: 11-18.

19. Kiang D, Yagi S, Kantardijieff KA, et al. Molecular characterization of variant rhinovirus from an outbreak associated with uncommonly high mortality. J Clin Virol. 2007; 38: 227-237.

20. Kiang D, Kalra I, Yagi S, et al. Assay for 5' noncoding region analysis of all human rhinovirus prototype strains. J Clin Microbiol. 2008; 46: 3736-3745.

21. Tamura K, Stecher G, Peterson D, et al. MEGA6: Molecular evolutionary genetics analysis version 6.0. Mol Biol Evol. 2013; 30: 2725-2729.

22. Chun JK, Lee JH, et al. Establishing a surveillance network for severe 
lower tract infections in Korean infants and children. Eur $J$ Clin Microbiol Infect Dis. 2009; 28: 841-845.

23. He Y, Lin GY, Wang Q, et al. A 3-year prospective study of the epidemiology of acute respiratory viral infections in hospitalized children in Shenzhen, China. Influenza Other Respir Viruses 2014; 8: 443-451.

24. Pretorius MA, Madhi SA, Cohen C, et al. Respiratory viral coinfections identified by a 10-plex real-time Reverse-transcription polymerase chain reaction assay in patients hospitalized with severe acute respiratory illness-South Africa, 2009-2010. J Infect Dis. 2012; 206: S159-S165.

25. Piotrowska Z, Vazquez M, Shapiro ED, et al. Rhinoviruses are a major cause of wheezing and hospitalization in children less than 2 years of age. Pediatr Infect Dis J. 2009; 28: 25-29.

26. Gugten AC, Zalm MM, Uiterwaal CSPM, et al. Human rhinovirus and wheezing: short and long-term associations in children. Pediatr Infect Dis J. 2013; 32: 827-833.

27. Iwane MK, Prill MM, Lu X, et al. Human rhinovirus species associated with hospitalizations for acute respiratory illness in young US children. $J$ Infect Dis. 2011; 204: 1702-1710.

28. Nair H, Nokes DJ, Gessner BD, et al. Global burden of acute lower respiratory infections due to respiratory syncytial virus in young children: a systematic review and meta-analysis. Lancet. 2010; 375: 1545-1555.

29. McGuiness CB, Boron ML, Saunders B, et al. Respiratory syncytial virus surveillance in the United States, 2007-2010. Pediatr Infect Dis J. 2014; 33: 589-594.

30. Respiratory syncytial virus infection, January 2014-September 2018. Infectious Agents Surveillance Report (IASR). 2018; 39: 207-209.

31. Shobugawa Y, Takeuchi T, Hibino A, et al. Occurrence of human respiratory syncytial virus in summer in Japan. Epidemiol Infect. 2017; 145: 272-284.

32. Weber MW, Mulholland EK, Greenwood BM, et al. Respiratory syncytial virus infection in tropical and developing countries. Trop Med Int Health. 1998; 3: 268-280. 
33. Sugaya N, Shinjoh M, Mitamura K, et al. Very low pandemic influenza A (H1N1) 2009 mortality associated with early neuraminidase inhibitor treatment in Japan: analysis of 1000 hospitalized children. J infect. 2011; 63: 288-294.

34. Kahn JS. Epidemilogy of human metapneumovirus. Clin Microbiol Rev. 2006; 19: 546-557

35. Osterhaus A, Fouchuer R. Human metapneumovirus in the community. Lancet. 2003; 361: 890-891.

36. Pecchini R, Berezin EN, Souza MC, et al. Parainfluenza virus as a cause of acute respiratory infection in hospitalized children. Braz J Infect Dis. 2015; 19: 358-362.

37. Weinberg GA. An underappreciated cause of pediatric respiratory mortality. Pediatr Infect Dis J. 2006; 25: 447-448.

38. Matoba Y, Abiko C, Ikeda T, et al. Detection of human coronavirus 229E, HKU1, NL63, and OC43 between 2010 and 2013 in Yamagata, Japan. Jpn J Infect Dis. 2015; 68: 138-141.

39. Meijer A, van der Sandan S, Snijders BE, et al. Emergence and epidemic occurrence of enterovirus 68 respiratory infections in the Netherland in 2010. Virology. 2012; 423: 49-57.

40. Imamura T, Oshitani H. Global reemergence of enterovirus D68 as an important pathogen for acute respiratory infections. Rev Med Virol. 2015; 25: $102-114$

41. Messacar K, Schreiner TL, Maloney JA, at el. Cluster of acute flaccid paralysis and cranial nerve dysfunction temporally associated with an outbreak of enterovirus D68 in children in Colorado, USA. Lancet. 2015; 385: 1662-1671.

42. Aliabadi N, Messacar K, Pastula DM, et al. Enterovirus D68 infection in children with acute flaccid myelitis, Colorado, USA, 2014. Emerg Infect Dis. 2016; 22: 1387-1394.

43. Kaida A, Iritani N, Yamamoto SP, et al Distinct genetic clades of enterovirus D68 detected in 2010, 2013, and 2015 in Osaka city, Japan. PLoS ONE. 2017; 13: e0184335.

44. Haraguchi K, Sato T, Moriyama K, et al. Accumulation of three pediatric 
cases of acute flaccid myelitis in autumn 2015 in Nagasaki, Japan. No to Hattatsu. 2017; 49: 408-412.

45. Sentilhes AC, Choumlivong K, Celhay O, et al. Respiratory virus infections in hospitalized children and adults in Lao PDR. Influenza Other Respir Viruses. 2013; 7: 1070-1078.

46. Pedraza-Bernal AM, Rodrigues-Martines CE, Acuna-Cordero RA, et al. Predictors of severe disease in hospitalized population of children with acute viral lower respiratory tract infections. J Med Virol. 2016; 88: 754-759.

47. Winther B, Hayden FG, Hendley JO. Picornavirus infections in children diagnosed by RT-PCR during longitude surveillance with weekly sampling: association with symptom illness and effect of season. $J$ Med Virol. 2006; 78: 644-650.

48. Wright PF, Deatly AM, Karron RA, et al. Comparison of results of detection of rhinovirus by PCR and viral culture in human nasal wash specimens from subjects with and without clinical symptoms of respiratory illnesss. J Clin Microbiol. 2007; 45: 2126-2129.

49. Kim EA, Lee KS, Primack SL, et al. Viral peumonias in adults: radiologic and pathologic findings. Radiograph. 2002; 22: S137-S149. 
Table 1. Clinical Feature and Severity of Patients According to Viral Etiology

\begin{tabular}{|c|c|c|c|c|c|c|c|}
\hline & \multirow{2}{*}{$\begin{array}{l}\text { No virus } \\
\mathrm{n}=114\end{array}$} & \multirow{2}{*}{$\begin{array}{l}\text { Any virus } \\
\mathrm{n}=259\end{array}$} & \multicolumn{5}{|c|}{ Detected as a single virus } \\
\hline & & & $\begin{array}{c}\text { HRV } \\
\mathrm{n}=107\end{array}$ & $\begin{array}{c}\mathrm{RSV} \\
\mathrm{n}=74\end{array}$ & $\begin{array}{l}\mathrm{hMPV} \\
\mathrm{n}=14\end{array}$ & $\begin{array}{c}\text { EV-D68 } \\
\mathrm{n}=9\end{array}$ & $\begin{array}{c}\text { Respirovirus } \\
\mathrm{n}=6\end{array}$ \\
\hline Age, median months (IQR) & $15.5(7-32)$ & $16(6-35)$ & $24(10-41)$ & $\underline{8.5(2-16) g}$ & $33(14-51)$ & $38(29-51)$ & $13(9-20.75)$ \\
\hline History of asthma (\%) & $8(6.9)$ & $\underline{46(18.8)^{\mathrm{a}}}$ & $\underline{22(20.6)}{ }^{\mathrm{e}}$ & $3(2.8)$ & $3(2.8)$ & $\underline{5(55.6)^{\mathrm{k}}}$ & $2(33.3)$ \\
\hline Underlying disease (\%) & $29(25.4)$ & $50(19.3)$ & $24(22.4)$ & $\underline{10(13.5)^{h}}$ & $3(21.4)$ & $1(11.1)$ & $1(16.7)$ \\
\hline Pneumonia (\%) & $71(61.7)$ & $\underline{114(44.0)}^{\mathrm{b}}$ & $\underline{49(45.8)^{\mathrm{f}}}$ & $\underline{28(26.1)^{\mathrm{i}}}$ & $10(71.4)$ & $6(66.7)$ & $5(83.3)$ \\
\hline $\mathrm{O}_{2}$ supplement $(\%)$ & $47(40.9)$ & $\underline{137(52.8) \mathrm{c}}$ & $53(49.5)$ & $\underline{44(59.5) \mathrm{j}}$ & $7(50.0)$ & $3(33.3)$ & $3(50.0)$ \\
\hline $\begin{array}{l}\text { Length of hospital stay, } \\
\text { median days (IQR) }\end{array}$ & $5(4-6)$ & $5(4-7)$ & $5(4-7)$ & $6(4-7)$ & $5(4-7)$ & $5(5-6)$ & $6(5.25-6.25)$ \\
\hline PICU stay (\%) & $3(2.6)$ & $\underline{0}^{\mathrm{d}}$ & 0 & 0 & 0 & 0 & 0 \\
\hline Death & 0 & 0 & 0 & 0 & 0 & 0 & 0 \\
\hline
\end{tabular}

PICU, pediatric intensive care unit. IQR, interquartile range.

$P$ values, based on comparison with patients with no detectable virus, were calculated by Logistic regression analysis.

a $P<0.001$. b $P=0.001$. c $P=0.025$. d $P=0.013$. e $P<0.001$. ${ }^{\text {f }} P=0.019$. g $P<0.001$. h $P=0.032 .{ }^{\text {i }} P=0.001$. j $P=0.005$. k $P<0.001$. 
Table 2. Clinical Features and Severity of Patients with any Detectable Virus According to Pre-Existing Medical Conditions

\begin{tabular}{|c|c|c|c|c|c|}
\hline Virus positive patients & $\begin{array}{l}\text { Previously healthy } \\
\text { n }=168\end{array}$ & $\begin{array}{l}\text { History of asthma } \\
\qquad \mathrm{n}=41\end{array}$ & $P$ & $\begin{array}{l}\text { Underlying diseases } \\
\qquad \mathrm{n}=50\end{array}$ & $P$ \\
\hline Age, median months (IQR) & $11(3-24)$ & $34(24-53)$ & $<0.001$ & $26.5(11-43)$ & $<0.001$ \\
\hline Pneumonia (\%) & $72(42.9)$ & $16(39.0)$ & 0.656 & $26(52.0)$ & 0.254 \\
\hline $\mathrm{O}_{2}$ supplement $(\%)$ & $66(39.3)$ & $28(68.3)$ & 0.001 & $43(86.0)$ & $<0.001$ \\
\hline $\begin{array}{l}\text { Length of hospital stay, } \\
\text { median days (IQR) }\end{array}$ & $5(4-6)$ & $5(4-7)$ & 0.198 & $7(6-10)$ & $<0.001$ \\
\hline PICU stay (\%) & 0 & 0 & NA & 0 & NA \\
\hline
\end{tabular}

IQR, interquartile range. PICU, pediatric intensive care unit. NA, not available.

$P$ values, based on comparison with previously healthy patients, were calculated by Pearson chi-square. Median age and length of hospital stay was calculated by Mann-Whitney U test. 
Figure 1. Flow chart of the study for the detection of viral pathogens

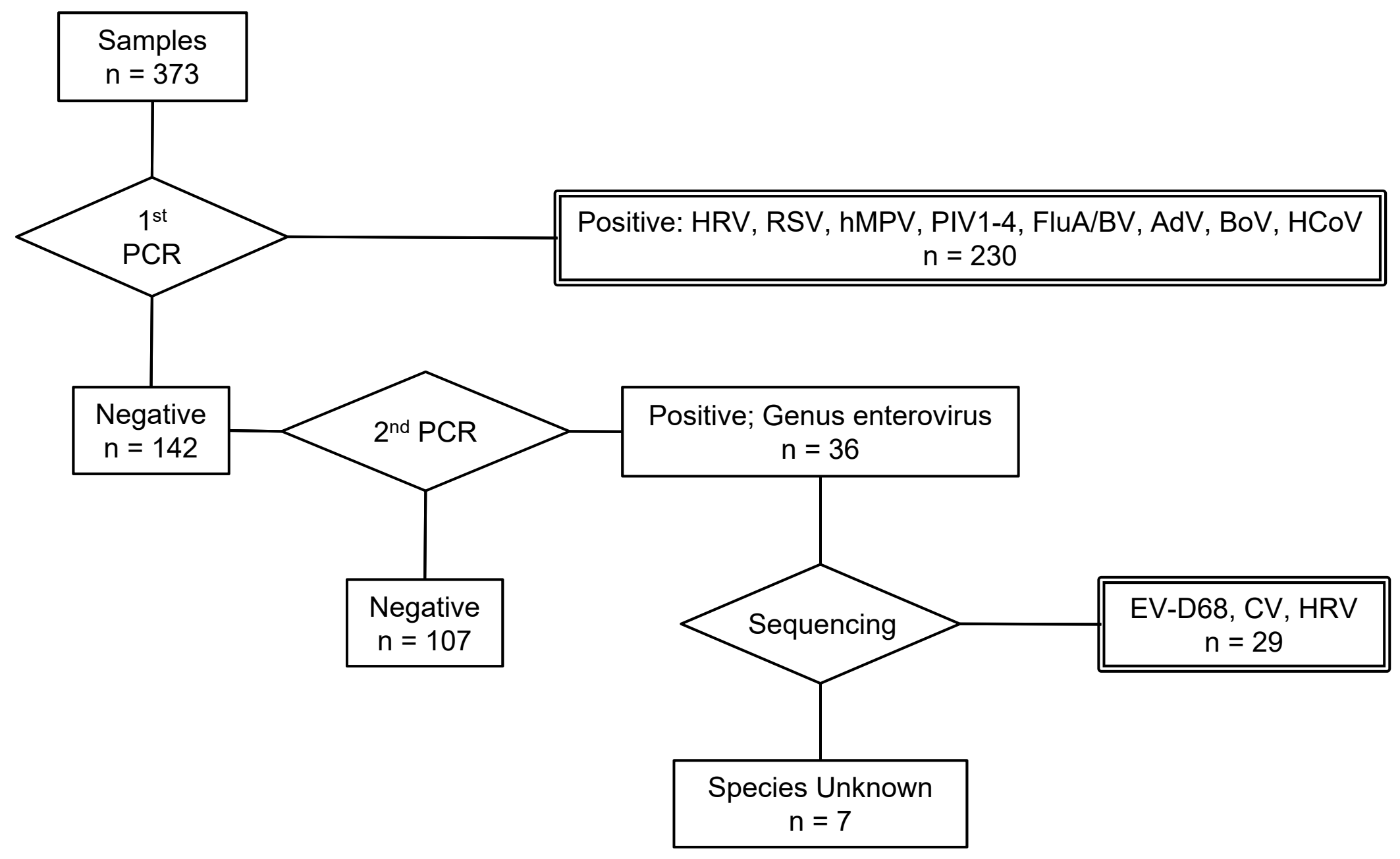


Figure 2. Monthly distribution of the 5 major viruses 2013-2015

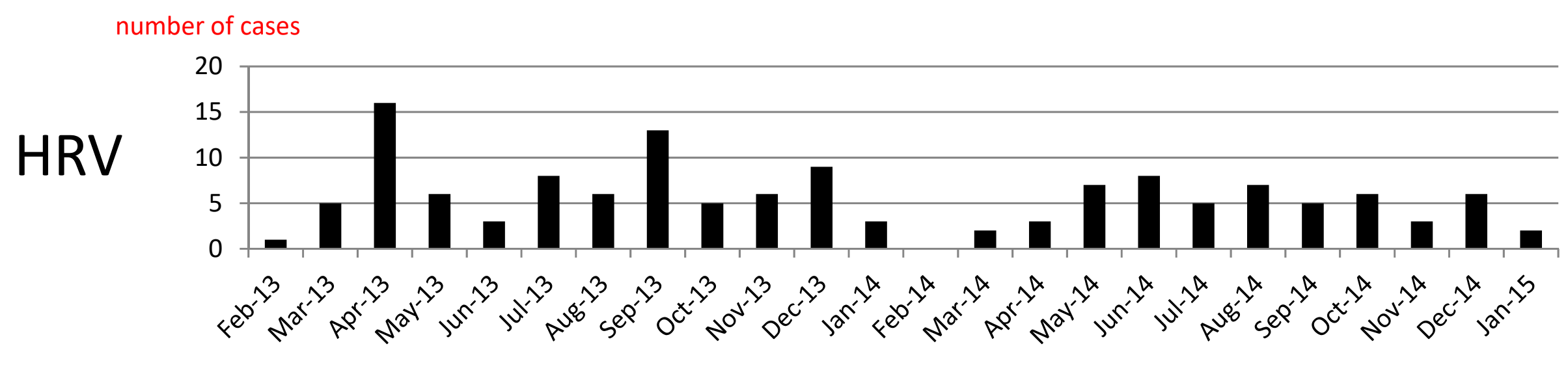

number of cases

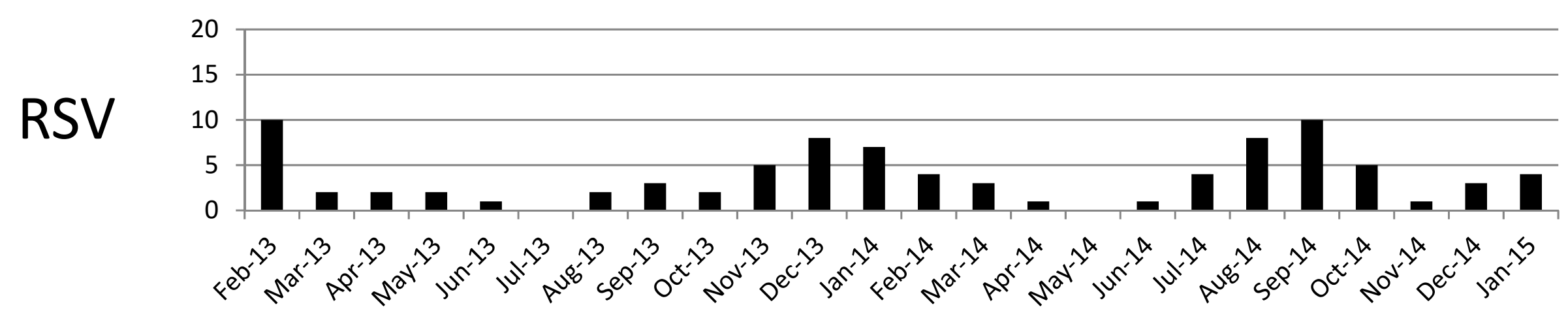

number of cases 
Number of cases

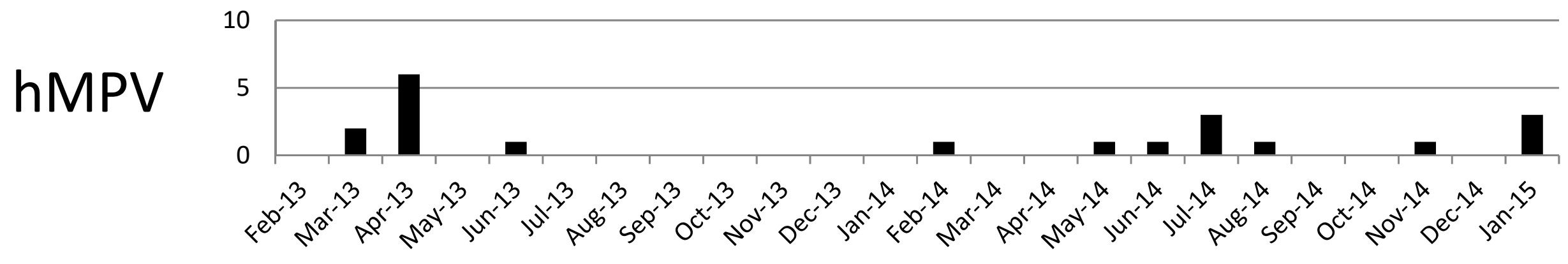

Number of cases

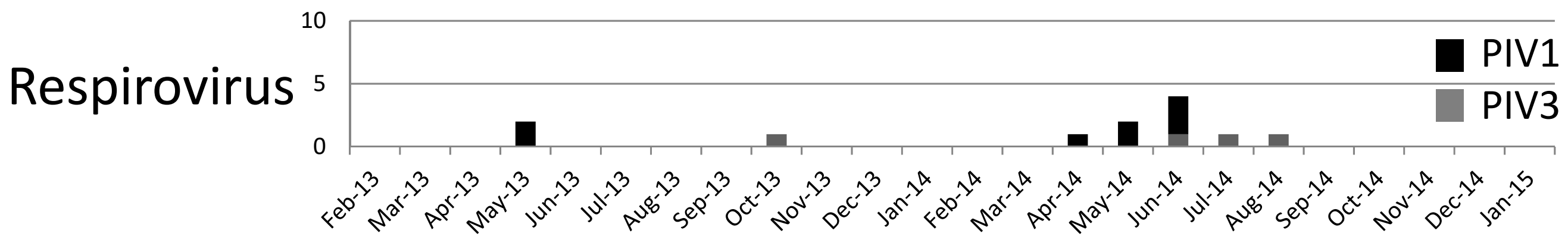

Number of cases

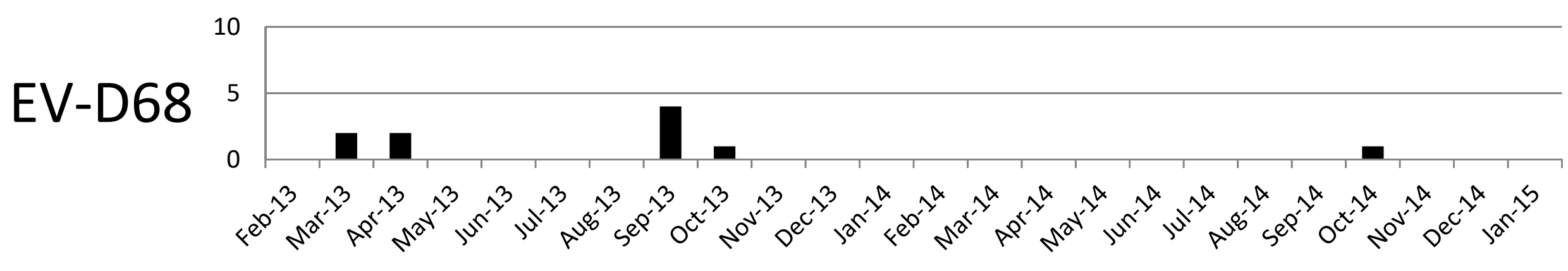

